OPEN ACCESS

Edited by:

Mathieu Vernier,

McGill University, Canada

Reviewed by:

Fernando Guimaraes, University of Queensland, Australia Frank M. Cichocki,

University of Minnesota Twin Cities,

United States

*Correspondence:

Subramaniam Malarkannan smalarkannan@versiti.org;

subramaniam.malarkannan@bcw.edu

${ }^{\dagger}$ Present address:

Chao Yang,

La Jolla Institute for Immunology, San

Diego, CA, United States

Specialty section:

This article was submitted to

Signaling,

a section of the journal

Frontiers in Cell and Developmental

Biology

Received: 27 May 2020

Accepted: 16 October 2020 Published: 10 November 2020

Citation:

Yang C and Malarkannan S (2020) Transcriptional Regulation of NK Cell

Development by mTOR Complexes.

Front. Cell Dev. Biol. 8:566090.

doi: 10.3389/fcell.2020.566090

\section{Transcriptional Regulation of NK Cell Development by mTOR Complexes}

\author{
Chao Yang ${ }^{1,2+}$ and Subramaniam Malarkannan 1,2,3,4* \\ ${ }^{1}$ Laboratory of Molecular Immunology and Immunotherapy, Versiti Blood Research Institute, Milwaukee, WI, United States, \\ ${ }^{2}$ Department of Microbiology and Immunology, Medical College of Wisconsin, Milwaukee, WI, United States, ${ }^{3}$ Department \\ of Medicine, Medical College of Wisconsin, Milwaukee, WI, United States, ${ }^{4}$ Department of Pediatrics, Medical College \\ of Wisconsin, Milwaukee, WI, United States
}

The mechanistic target of Rapamycin (mTOR) is essential for multiple cellular processes. The unique roles of mTOR complex 1 (mTORC1) or mTOR2 in regulating immune functions are emerging. NK cells are the major lymphocyte subset of innate immunity, and their development and effector functions require metabolic reprogramming. Recent studies demonstrate that in NK cells, conditionally disrupting the formation of mTORC1 or mTOR complex 2 (mTORC2) alters their development significantly. Transcriptomic profiling of NK cells at the single-cell level demonstrates that mTORC1 was critical for the early developmental progression, while mTORC2 regulated the terminal maturation. In this review, we summarize the essential roles of mTOR complexes in NK development and functions.

Keywords: NK cell development, mTORC1, mTORC2, raptor, rictor

\section{INTRODUCTION}

The identification and characterization of the mechanistic target of Rapamycin (mTOR) are closely associated with the discovery of Rapamycin (Sirolimus). In 1964, a Canadian expedition discovered Rapamycin from the soil samples from the South Pacific island of Rapa Nui (Easter Island), which possessed high anti-fungi, anti-tumor, and immunosuppressive effects (Vezina et al., 1975; Martel et al., 1977; Eng et al., 1984). Georges Nogrady, a microbiologist, collected the soil samples from different parts of the Easter Island to search for why the barefoot islanders did not get tetanus. In 1975, it was found that the Streptomyces hygroscopicus produced an anti-fungal compound that was able to inhibit the growth of Candida albicans, Microsporum gypseum, and Trichophyton granulosum (Sehgal et al., 1975; Vezina et al., 1975). In 1982, the immunosuppressive and antitumor functions of Rapamycin were discovered (Eng et al., 1984). Chung et al. (1992) found that Rapamycin forms complexes with peptidyl-prolyl isomerase FKBP1A (also known as FKBP12) to mediate its anti-proliferative functions (Kuo et al., 1992). The genetic screening of Rapamycinresistance led to the identification of the TOR/DRR gene. In 1994, the mTOR-FKBP12 complex in mammalian cells was identified (Brown et al., 1994; Sabatini et al., 1994; Sabers et al., 1995). For the past 25 years, numerous researchers have worked on mTOR protein and defined its essential role in cell growth and functions (Sabatini, 2017).

Mechanistic target of Rapamycin is an evolutionarily conserved $289 \mathrm{kDa}$ serine/threonine kinase of phosphoinositide 3-kinase-related protein kinases (PIKK, Figure 1A) (Saxton and Sabatini, 2017). mTOR forms two structurally distinct complexes, mTOR complex 1 (mTORC1) and mTOR complex 2 (mTORC2) with unique substrate specificities and functions (Saxton and Sabatini, 2017). mTORC1 consists of mTOR, Raptor (regulatory protein associated with mTOR), mLST8 


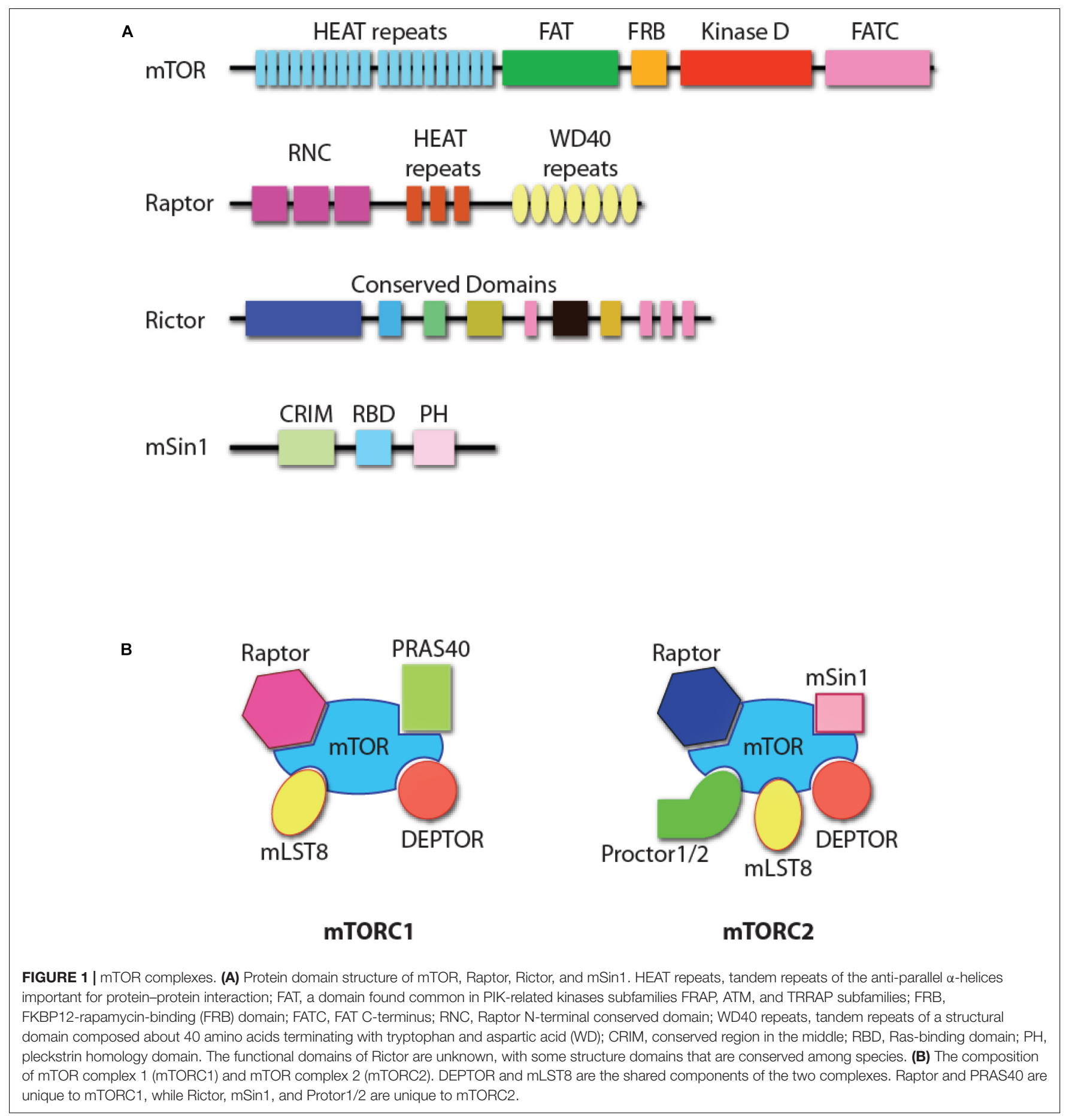

(mammalian lethal with Sec13 protein 8), PRAS40 (prolinerich Akt substrate of $40 \mathrm{kDa}$ ), and DEPTOR (DEP domaincontaining mTOR interacting protein, Figure 1B) (Saxton and Sabatini, 2017). Genetic studies have demonstrated that Raptor is the essential component in the formation of mTORC1 (Hara et al., 2002; Kim et al., 2002). mTORC2 comprises mTOR, Rictor (rapamycin-insensitive companion of mTOR), $\mathrm{mSin} 1$ (mammalian stress-activated protein kinase interacting protein 1), Protor1/2 (protein observed with Rictor-1/2), mLST8, and DEPTOR (Figure 1B) (Saxton and Sabatini, 2017). Both Rictor and $\mathrm{mSin} 1$ are essential for the formation of mTORC2 (Jacinto et al., 2004, 2006; Sarbassov et al., 2004; Frias et al., 2006; Yang et al., 2006).

There are five major structural domains of mTOR. This includes the tandem HEAT domain, the FAT (FRAP, ATM, and TRRAP, all PIKK family members) domain, the FRB 
(FKBP12/rapamycin binding) domain, and the FATC (FAT C-terminus) domain (from $\mathrm{N}$-terminus to C-terminus, Figure 1A) (Yang and Guan, 2007). The tandem HEAT domain mediates the protein-protein interaction between mTOR and Raptor, and the homodimerization of mTORC1 (Yip et al., 2010; Aylett et al., 2016; Baretic et al., 2016). Raptor contains a conserved domain in the $\mathrm{N}$-terminus and seven WD40 repeats, which may facilitate the interactions with mTOR or mTORC1-associated proteins. Rictor is also predicted to contain HEAT repeats and WD40 domains (Zhou et al., 2015). Pleckstrin homology $(\mathrm{PH})$ domains present in Rictor help mediate signal transduction and subcellular localization (Zhou et al., 2015). Another mTORC2 component, mSin1, has a central conserved domain, a Ras-binding domain, and a C-terminal $\mathrm{PH}$ domain (Schroder et al., 2004, 2007). The PH domain of mSin1 interacts with the kinase domain of mTOR (Liu et al., 2015). The different composition of the accessory proteins determines that only the FRB domain in mTORC1, but not mTORC2, is accessible to the FKBP12/Rapamycin complex. This results in the inhibition of mTORC1, but not mTORC2. However, prolonged incubation of cells with Rapamycin does inhibit mTORC2 function primarily due to compromised formation of mTORC2, as rapamycin-bound $\mathrm{mTOR}$ protein cannot be incorporated into mTORC2 (Sarbassov et al., 2006). Significant progress has been made in defining the essential roles played by mTOR complexes in NK cells (Donnelly et al., 2014; Marcais and Walzer, 2014; Marcais et al., 2014, 2017; Nandagopal et al., 2014; Yang et al., 2016, 2018). In this review, we summarize the relevance of these findings in the context of NK cell development and functions.

\section{$\gamma_{C}$-UTILIZING CYTOKINE RECEPTORS LINK MTORC1 TO NK CELL DEVELOPMENT}

NK cells develop in the BM (Kondo et al., 1997). Common lymphoid progenitors (CLPs) give rise to the early innate lymphoid progenitors (EILPs) that differentiate into all three ILC lineages and conventional NK cells (Yang Q. et al., 2015). Development of $\mathrm{NK}$ cell is regulated by multiple commongamma chain-containing cytokine $(\gamma c, \mathrm{CD} 132)$ receptors that utilize $\mathrm{PI}(3) \mathrm{K}$, as a major signaling link to mTOR complexes (Figure 2). There are five members in the $\gamma_{c}$ family (IL-2, IL-4, IL-7, IL-15, and IL-21), all transduce their signaling via $\mathrm{PI}(3) \mathrm{K}$ and thereby mTOR complexes (Boulanger and Garcia, 2004). The distinctions among the $\gamma c$ chain receptor family come from the unique $\alpha$-chain utilization and the differential activation of unique STATs. The earliest indication of the commitment to the NK lineage is defined by the expression of the IL-15/IL-2 receptor $\beta$ chain (CD122) (Rosmaraki et al., 2001). Thus, the initial commitment of NK cells is tightly associated with the optimal functions of mTOR complexes.

Both IL-15 and IL-2 can bind to the receptor complex formed by IL-2/15R and $\gamma c$ chain and transduce the signals primarily via PI(3)K (Bamford et al., 1994; Giri et al., 1994; Grabstein et al., 1994). The essential role of $\gamma c$ revealed by the fact that individuals with common gamma chain mutations develop severe immunodeficiency with nearly complete loss of NK cells (Noguchi et al., 1993). IL-2 binds to the heterotrimeric receptors composed of CD122, CD132, and IL-2R $\alpha$ (CD25) with high affinity (Rickert et al., 2005; Stauber et al., 2006). In contrast, IL-15 has a similar high-affinity binding with IL-15R $\alpha$ (CD215) alone (Giri et al., 1995). Among these two cytokines, IL-15 has been shown to be critical for NK cell development and effector functions (Becknell and Caligiuri, 2005; Marcais et al., 2013). A low dose of IL-15 is sufficient to sustain survival signaling in NK cells, while a high dose of IL-15 promotes NK cell proliferation and effector molecules expression (Marcais et al., 2013, 2014). Through the genetic ablation of individual cytokine members or receptors, the importance of IL-15 in the development of NK cells is now well established. CD132 deficiency in mice also eradicates the NK compartment (DiSanto et al., 1995). Genetic deletion of Il15 or Il15ra but not Il2 results in a similar loss of mature NK cells seen in the $\gamma c$ chaindeficient mice, firmly establishing the central role of IL-15 in the development of NK cells (Lodolce et al., 1998; Kennedy et al., 2000; Vosshenrich et al., 2005). As the expression of IL-15 and IL-15R $\alpha$ occurs in the same cells, this high-affinity interaction results in membrane-bound IL-15/IL-15R $\alpha$ complex (Giri et al., 1995). Thus, the IL-15 signaling initiates through the transpresentation of IL-15 anchored by IL-15R $\alpha$ in the neighboring cells to the IL-2/15R $\beta / \gamma$ c complex-bearing cells (Dubois et al., 2002; Mortier et al., 2008). The role of mTOR in the IL-15dependent developmental progression and priming of NK cells are well established (Marcais et al., 2014; Nandagopal et al., 2014; Mah et al., 2017), which we discuss in the following section.

\section{IL-15R UTILIZES PI(3)K TO ACTIVATE MTORC1 IN NK CELLS}

Three major pathways, including the Jak1/3-Stat5a/b, the PI(3)KmTOR, and the MAPK (Boyman and Sprent, 2012), exist downstream of IL-15R. The first pathway involves Jak-mediated activation of Stats. Upon IL-15 binding, IL-2/15R $\beta / \gamma$ c complex recruits Jak1 and Jak3 (Boussiotis et al., 1994; Miyazaki et al., 1994; Russell et al., 1994; Zhu et al., 1998). Jak1 and Jak3 phosphorylate Tyr392 and Tyr510 at the H-region, which serves as critical docking sites for downstream functional proteins, including transcription factors Stat5a and Stat5b (Truitt et al., 1994; Fujii et al., 1998). Serving as the proximal signaling module, it is not surprising that the loss of Jak3 results in the absence of NK cells in mice (Park et al., 1995). Downstream of Jak1/3, both Stat5a and Stat5b are essential to maintain the homeostasis of NK cell pool in mice. Thus, Stat5b deficiency results in a severe loss of NK cells (Imada et al., 1998; Eckelhart et al., 2011). Recent work has demonstrated a correlation between the absolute number of splenic NK cells and the copy number of Stat5a/b. The second pathway initiated downstream of the IL-15 receptor involves the PI(3)K-mTOR axis. Class IA PI(3)Ks include $\mathrm{p} 100 \alpha$, $\mathrm{p} 100 \beta$, and $\mathrm{p} 100 \delta$, that are recruited to the membrane via the regulatory subunit $\mathrm{PI}(3) \mathrm{K}-\mathrm{p} 85 \alpha$ (Okkenhaug, 2013). Both $\mathrm{p} 100 \beta$ and $\mathrm{p} 100 \delta$ are essential for the development of NK cells, although the detailed mechanisms require further investigations 


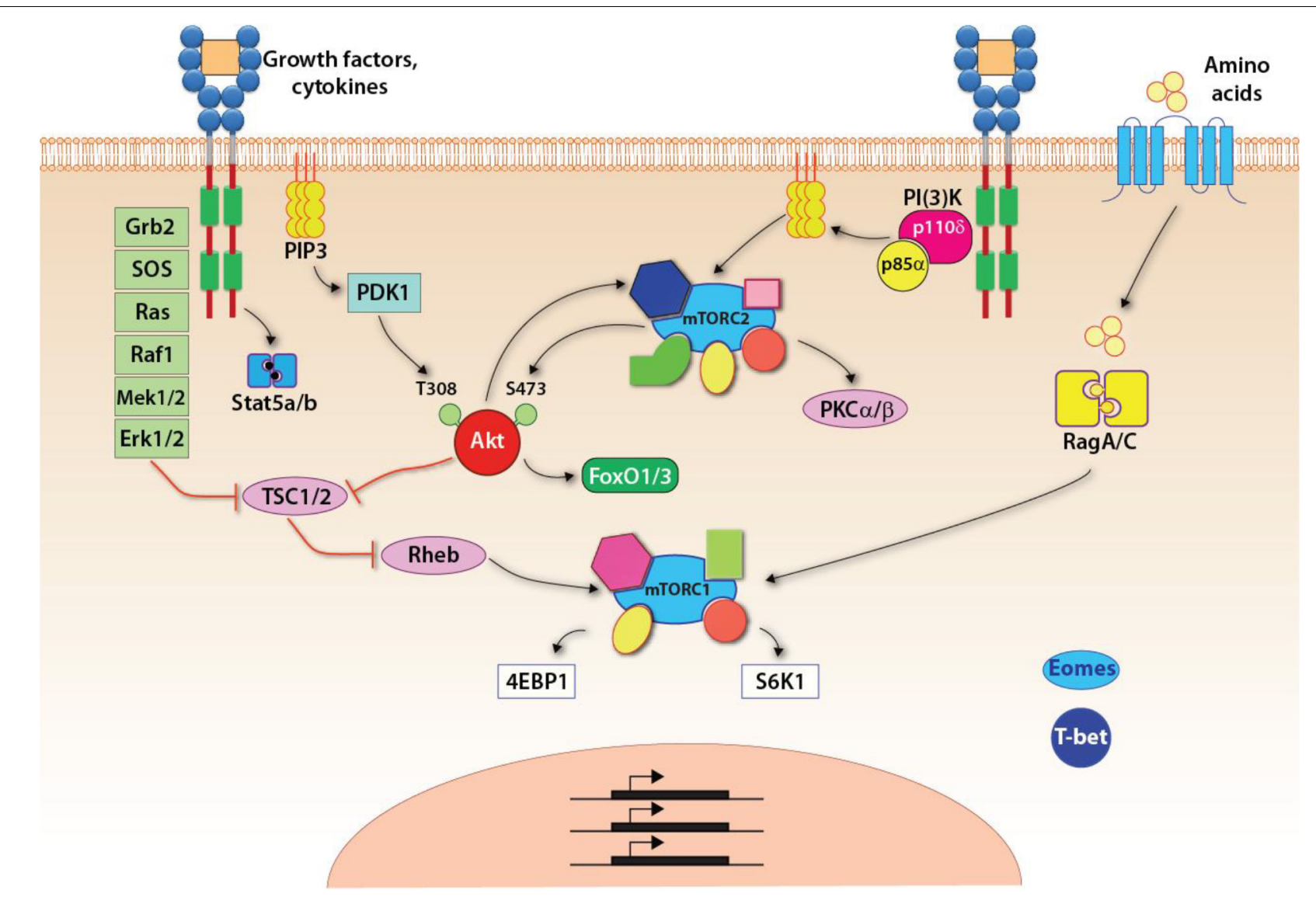

FIGURE 2 | Signaling pathways up and downstream of mTOR complexes. Upon growth factors- or cytokine-mediated activation, three major pathways are initiated: the Jak-Stat5 pathway, the PI(3)K-Akt-mTOR pathway, and the Ras-Raf-Mek-Erk1/2 MAPK pathway. Specific to the mTORC1 pathway, the tuberous sclerosis complex (TSC) functions as a GTPase-activating protein (GAP), which inhibits the activity of Rheb, a small GTPase absolutely required for the activation of mTORC1. Thus, TSC is a central negative regulator of mTORC1 signaling. The activated Akt or Erk, downstream of PI(3)K-Akt or MAPK pathway, respectively, phosphorylates TSC and inhibits its GAP activity resulting in the activation of mTORC1. In addition, amino acids are required for anchoring mTORC1 on the lysosomal membrane where Rheb locates. This is achieved through the RagA/C.

(Kim et al., 2007; Tassi et al., 2007; Guo et al., 2008). Downstream of $\mathrm{PI}(3) \mathrm{K}$, mTOR initiates the functions of distinct transcription factors that govern the development and functions of NK cells (Marcais et al., 2014).

The activation of mTORC1 is tightly controlled by the availability of nutrients as mTORC1-mediated anabolism requires sufficient energy and metabolites for the synthesis of macromolecules. Growth factor and mitogen-defendant pathways are potent stimuli for the activation of mTORC1 (Figure 2). A central regulatory mechanism that governs the activation of mTORC1 through pro-growth signaling is the heterotrimeric tuberous sclerosis complex (TSC) comprising TSC1, TSC2, and TBC1D7 (Dibble et al., 2012). TSC functions as a GTPase activating protein (GAP) that inhibits the activity of small GTPase Rheb, which binds and activates mTORC1 (Inoki et al., 2003; Tee et al., 2003; Long et al., 2005). Both PI(3)K-PDK1-Akt and the third pathway downstream of IL-15R involving MAPK promote the phosphorylation of TSC2 and inhibit the function of TSC (Inoki et al., 2002; Manning et al., 2002; Roux et al., 2004; Ma et al., 2005). The inhibition of TSC allows the GTP-bound Rheb to activate mTORC1. Recent studies have shown that TSC1, a negative regulator of mTORC1 and mTORC2, was not required for the terminal maturation and survival of NK cells (Yang et al., 2016). Also, the cytotoxic potentials and the ability to generate inflammatory cytokines were intact in the absence of TSC1. However, TSC1 was needed to limit the exhaustive proliferation of developing immature NK (iNK) cells downstream of IL-15R. Exposure of iNK cells to IL-15 significantly upregulated the expression of TSC1. These findings validate the essential role played by TSC1 in regulating the functions of mTORC1 in iNK cells.

Besides the cytokine-mediated stimuli, sensing the levels of amino acids in the cytoplasm also activates mTORC1. The presence of amino acids in the cytosol anchors mTORC1 to the lysosomal membrane through the heterodimeric Rag GTPase (Kim et al., 2008; Sancak et al., 2008). This enables activation of mTORC1 by Rheb, which is also present in the lysosomal membrane (Menon et al., 2014). Under cellular stress, the activation of mTORC1 is suppressed mainly through AMPK-mediated phosphorylation and activation of TSC2 or 
direct phosphorylation of Raptor (Shaw et al., 2004; Gwinn et al., 2008). Indeed, a higher level of KLRG1 receptor expression induced the activation of AMPK that negatively regulated NK cell effector functions (Muller-Durovic et al., 2016). Inhibition of Rag GTPases blocks mTORC1-mediated functions (Kalender et al., 2010). As activation of mTORC1 promotes NK cell growth and proliferation, the downstream targets of $\mathrm{mTORC} 1$ are often involved in the syntheses of proteins, lipids, and nuclear acids. The best-characterized downstream targets of mTORC1 are 4EBPs and S6K1, both of which are highly involved in the protein synthesis. The $5^{\prime}$ cap-dependent mRNA translation requires the formation of the eIF4F complex (Merrick, 2004). One vital component in the eIF4F complex is eIF4E, which recognizes the $5^{\prime}$-cap of mRNA (Merrick, 2004). 4EBPs bind eIF4E and inhibit the assembly of the eIF4F complex, which in turn inhibits the $5^{\prime}$ cap-dependent mRNA translation (Richter and Sonenberg, 2005). mTORC1 sequentially phosphorylates multisites on $4 \mathrm{EBPs}$ and dissociate $4 \mathrm{EBPs}$ from eIF4E to promote 5'cap-dependent mRNA translation (Brunn et al., 1997; Gingras et al., 1999). Studies have also demonstrated that the mTORC14 EBPs axis mostly affects a group of mRNAs named $5^{\prime}$-TOP mRNA, which contains the $5^{\prime}$-terminal oligopyrimidine motif (Meyuhas, 2000; Thoreen et al., 2012). The majority of protein products translated from the $5^{\prime}$-TOP mRNA are involved in protein synthesis (Meyuhas, 2000).

Another well-established mTORC1 target, S6K1, also regulates protein translation. mTORC1 phosphorylates the hydrophobic motif of S6K1 at Thr389 that results in conformational changes leading to the phosphorylation by PDK1 (Pearson et al., 1995; Alessi et al., 1998; Pullen et al., 1998). The phosphorylated and activated S6K1 promotes 5 'cap-dependent mRNA translation by phosphorylating eIF4B, a critical component of eIF4F complex (Holz et al., 2005). S6K1 can also phosphorylate and promote the degradation of PDCD4, a negative regulator of mRNA translation (Dorrello et al., 2006). Besides promoting protein synthesis, S6K1 also phosphorylates and promotes degradation of PDCD4, a negative regulator of mRNA translation (Dorrello et al., 2006). Besides promoting protein synthesis, S6K1 also phosphorylates and activates sterol regulatory element-binding protein 1 and 2 (SREBP and SREBP2), which promotes de novo lipid synthesis that is critical for cell growth and proliferation (Duvel et al., 2010). In addition to S6K1, mTORC1 has also been shown to promote the SREBP pathway through the regulation of lipin 1 (Peterson et al., 2011). In addition to lipid metabolism, recent studies have established the mTORC1-S6K1 axis in regulating the de novo purine and pyrimidine synthesis (Ben-Sahra et al., 2013, 2016; Robitaille et al., 2013). How mTORC1 regulates to achieve optimal NK cell development needs to be explored in the future.

\section{IL-2R AND IL-15R INITIATE MTORC2 ACTIVATION IN NK CELLS}

The precise molecular mechanism by which mTORC2 regulates NK cell development and functions and the interplay between mTORC1 and mTORC2 in NK cells are under active investigations. Recent studies have established the requirement of mTORC2 function in NK cell development (Marcais and Walzer, 2014; Marcais et al., 2014, 2017; Yang et al., 2018, 2020). Under homeostatic conditions, both mTORC1 and mTORC2 are activated at relatively higher levels in iNK cells compared to mature NK cells (Marcais et al., 2017). Unlike the specific inhibition of mTORC1 by Rapamycin, currently, there is no mTORC2-specific inhibitor, which hinders the study of mTORC2. The inhibition of mTORC2 activity by wortmannin, a specific $\mathrm{PI}(3) \mathrm{K}$ inhibitor, has led to the speculation that mTORC2 is downstream of the PI(3)K pathway (Sarbassov et al., 2005), which implies its activation downstream of $\gamma \mathrm{c}$-chain cytokine receptors such as IL-15R (Figure 2). Liu et al. (2015) have found that the $\mathrm{PH}$ domain of mSin1 interacts with the kinase domain of mTOR and inhibits the kinase activity of mTORC2. The PtdIns $(3,4,5) \mathrm{P}_{3}$ generated by $\mathrm{PI}(3) \mathrm{K}$ interacts with the $\mathrm{PH}$ domain and releases the inhibition of the kinase domain of mTOR. Besides this allosteric activation of mTORC2, Akt, downstream of $\mathrm{PI}(3) \mathrm{K}$, phosphorylates mSin1 at Thr86 site and promotes the activation of mTORC2 (Yang G. et al., 2015). Whether this phosphorylation also relieves the inhibition mediated by the $\mathrm{PH}$ domain remains unknown. Also, Zinzalla et al. (2011) have reported that PI(3)K signaling promotes the association of mTORC2 with the ribosomes, and this spatial regulation also induces the activation of $\mathrm{mTORC} 2$, although the mechanism is unknown.

The well-characterized downstream target of mTORC2 is Akt. The phosphorylation of Akt at the Ser473 site is exclusively mediated by mTORC2 and therefore is the standard measurement of mTORC2 activity (Frias et al., 2006; Guertin et al., 2006). Although Akt is upstream of mTORC1, phosphorylation of Ser473 on Akt does not seem to affect the activation of mTORC1 (Guertin et al., 2006). Mechanistically, phosphorylation of Thr308 mediated by PDK1, instead of Ser473, is critical for the kinase activity of Akt (Alessi et al., 1997; Hill et al., 2001), while the Ser473 phosphorylation seems to dictate the substrate specificity of Akt (Jacinto et al., 2006). Akt-mediated phosphorylation of FoxO1/FoxO3a requires mTORC2, and this axis is vital in regulating apoptosis and proliferation (Guertin et al., 2006; Jacinto et al., 2006). mTORC2 also phosphorylates PKC $\alpha$ that regulates cytoskeletal remodeling (Jacinto et al., 2004; Sarbassov et al., 2004). Subsequently, more members of the PKC family were found to be the targets of mTORC2 and involved in the regulation of cytoskeleton (Gan et al., 2012; Li and Gao, 2014). This reveals why perturbing the mTORC2 pathway has a significant negative impact on the cytotoxic potentials of NK cells that depends on cytoskeletal remodeling and vesicular trafficking.

The knowledge related to the interplay between mTORC1 and mTORC2 in NK cells is emerging. Interestingly, mTORC1 can indirectly influence the activation of mTORC2 through a negative feedback loop through S6K1-Grb2 or S6K1-IRS1 axis to inhibit insulin-mediated PI(3)K activation (Harrington et al., 2004; Shah et al., 2004; Hsu et al., 2011; Yu et al., 2011). Other studies have shown that mTORC1 positively regulates mTORC2 function by sustaining IL-15R-mediated signaling. In contrast, mTORC2 represses mTORC1-mediated effector functions of NK cells by repressing STAT5-mediated SLC7A5 expression (Wang et al., 2018). Further studies are warranted to determine 
both the independent and interdependent functions of mTORC1 and mTORC2 in NK cells.

\section{MTOR-DEPENDENT METABOLIC REPROGRAMMING IN NK CELLS}

Mechanistic target of Rapamycin complex 1-mediated glycolysis has been related to the function of NK cells (Donnelly et al., 2014; Mah et al., 2017). Marcais et al. (2014) demonstrated the critical role of mTOR in the proliferation and granzyme B expressionmediated by IL- 15 during viral infection using an NK cell-specific Mtor knockout mouse. In addition, the development of NK cells is significantly impaired in these mice (Marcais et al., 2014). Most of the functional defects have been attributed to mTORC1 due to comparable impairments induced by rapamycin (Donnelly et al., 2014; Nandagopal et al., 2014). TGF- $\beta$ suppresses the effector functions of NK cells through inhibition of mTORC1 (Viel et al., 2016). Earlier studies have shown that IL-2-mediated stimulation of NK cells in the presence of TGF- $\beta$ significantly reduced levels of oxidative phosphorylation, maximal respiration, and glycolytic capacity; but, not glycolysis (Viel et al., 2016). Presence of TGF- $\beta$ also reduced the expression of CD69, CD71, IFN- $\gamma$, and granzyme B. Treatment of these cells with TGF $\beta$ R 1 inhibitor reversed these effects except granzyme B. Lack of the TGF $\beta$ R2 in NK cells reduced the levels of granzyme B in NK cells, validating the link between TGF- $\beta$ and mTORC1. It is predicted that the effect of TGF- $\beta$ is mediated by a non-Smad pathway that involves PI(3)K/Akt signaling. Besides cytokinesmediated signaling, mTOR is also activated downstream of NK cell activating receptors, and its activity is associated with the responsiveness of the cells (Marcais et al., 2017).

The link between mTORs and mitochondrial functions is emerging (Cong et al., 2018; Summer et al., 2019). mTORmediated metabolic reprogramming is linked to mitochondrial and cell respiration (Zheng et al., 2019). The presence of NK cells within the tumor microenvironment has been well-established (Habif et al., 2019). However, the mechanistic basis for their inaction against the tumor cells is yet to be understood. Recent studies have shown that a hypoxic condition established by the tumor initiates and sustains the activation of mTOR-GTPase dynamin-related protein-1 (mTOR-Drp1) (Zheng et al., 2019). Phosphorylation is an essential event for the mitochondrial profission function of Drp1. This study revealed that a hypoxic environment leads to sustained mTOR activation via AKTTSC1/2 signaling in human NK cells. This hyperactivation of mTORC1 augmented the phosphorylation and activation of mTOR-Drp1, leading to mitochondrial fragmentation and failure in their anti-tumor effector functions. The sustained activation of Drp1 was mediated by an mTORC1/4EBP1-dependent translation and expression of mitochondrial fission process-1 (MTFP1) protein. MTFP1 mediates the phosphorylation of Drp1 potentially via a retrograde signaling pathway and the respective kinases. Recruitment of Drp1 to the mitochondria leads to its fragmentation and prevents their branching and hyperfusion (Morita et al., 2017). Thus, persistent activation of mTORC1 due to hypoxia can lead to a failure of NK cells. While these findings identify novel therapeutic targets, additional studies can help to define the mechanisms of NK cell impairments under non-hypoxic conditions.

\section{TRANSCRIPTIONAL REGULATION OF NK CELL DEVELOPMENT BY MTORC1 AND MTORC2}

The evolving transcriptome of developing mouse and human NK cells has recently deciphered (Crinier et al., 2018; Yang et al., 2018, 2019, 2020). These studies provide the opportunity to identify the transcriptional activation or repression during NK cell ontology. Generation of $\mathrm{Ncr}^{i \mathrm{iCre}}$-based conditional knockout mice for Raptor (Rptor; Rptor $r^{f l / f l} \mathrm{Ncr} 1^{\mathrm{Cre} / W T}$ ) and Rictor (Rictor; Rictor ${ }^{f l / f l} \mathrm{Ncr} 1^{\mathrm{Cre} / W T}$ )-encoding genes provided unique opportunities to perform focused analyses of NK cells (Figure 3). These murine models, combined with singlecell RNA sequencing (scRNA-seq) technology, have allowed investigators to define the unique role of mTOR complexes in the transcriptional regulation of NK cell development and functions (Yang et al., 2018). Single-cell RNA-sequencing technology has provided us an unprecedented insight into the transcriptomic profiles of NK cell heterogeneity and development (Crinier et al., 2018; Yang et al., 2019; Dogra et al., 2020). Using this approach, the transcriptional regulations mediated by mTORC1 and mTORC2 were recently determined (Yang et al., 2020).

In the bone marrow of the WT mice, single-cell transcriptome analyses reveal five distinct NK developmental subsets. They are an iNK cluster, three transitional NK (transNK1, transNK2, and transNK3) clusters, and a terminally mature NK (termNK) cluster. The iNK cluster represented the most immature stage with high expression of $C d 27$ and low expression of Itgam (CD11b) and Ly49s (Klra1/3/4/7/8/9), and high expression of $L t b, T h y 1, C d 3 d / g$, and $C d 7$. In contrast, the termNK cells were defined by the low expression of $C d 27$ and high expression of Itgam Gzma, Gzmb, and Klrg1. The transNK1 cluster possessed a high expression of genes encoding proteins involved in ribosomal biogenesis, including ribonucleoproteins (Nop10, Nhp2, Gar1, Npm1, Npm3), RNA modification enzymes (Mettl1, Ddx21, $F b l$ ), and GTPase related to nucleocytoplasmic transport (Ran, Ranbp1). Notably, some of the major metabolic pathways that are regulated by mTORC1, including glycolysis, oxidative phosphorylation, and fatty acid metabolism, were upregulated in the transNK1 cluster. This confirmed a direct role of mTORC1 in the early developmental stages of NK cells.

Lack of Raptor (mTORC1) resulted in significant NK cell developmental defects as the early stages (Yang et al., 2018). Conditional ablation of mTORC1 by the deletion of Raptor resulted in the blockade of NK cell development at the CD27 single-positive stage in the BM of Rptorfl/fl $N$ crl Cre $^{\mathrm{CWT}}$ mice. mTORC1 is required for the expression of Eomesodermin (Eomes) and the transition from CD27 SP to DP NK stage, while mTORC2 is required for the terminal CD11b SP NK cell maturation through the mTORC2-Akt ${ }^{S 473}$-FoxO1 axis (Yang et al., 2018). Eomes and T-bet belong to the T-box family of TFs, which control multiple aspects of NK cell development 

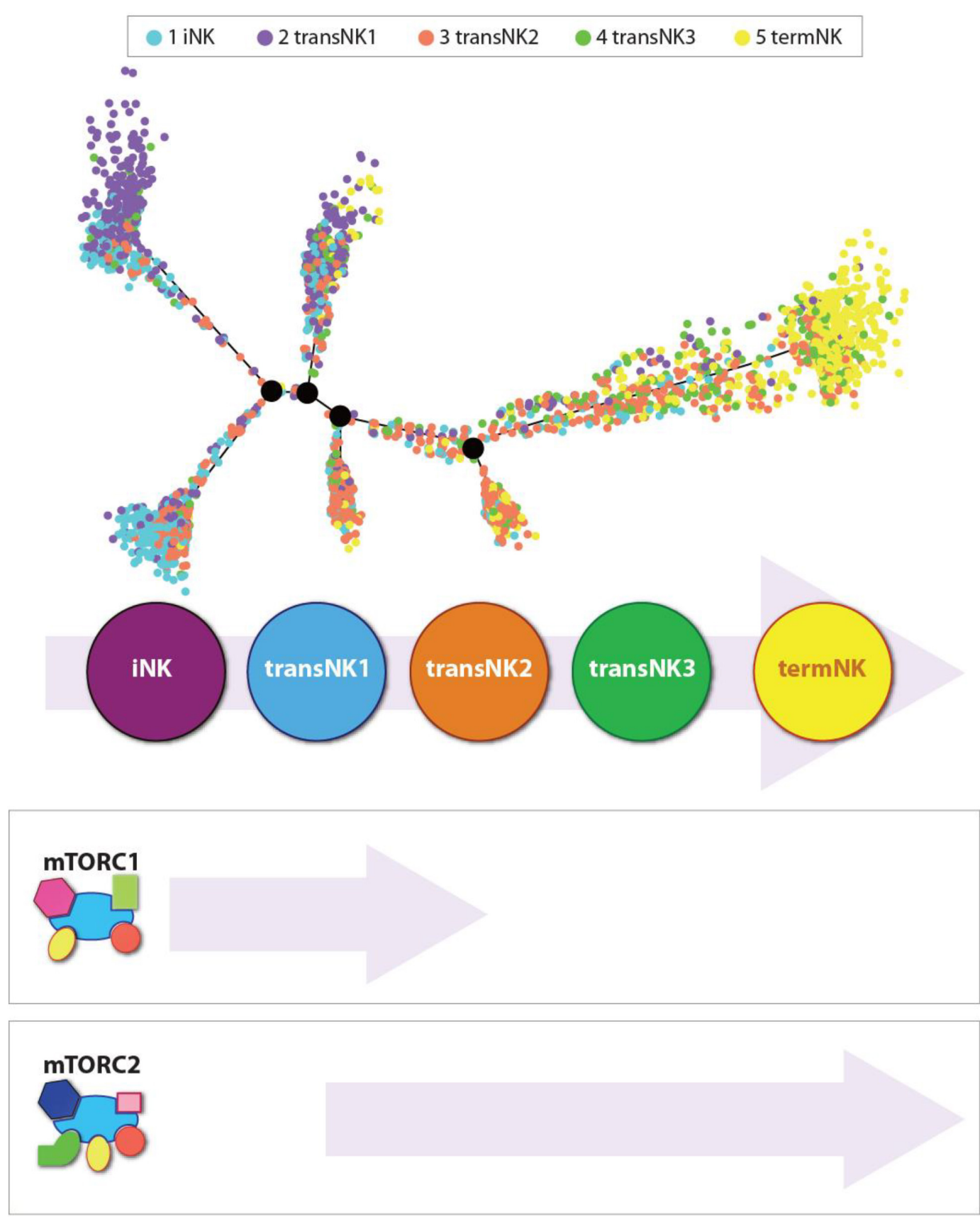

FIGURE 3 | Independent roles of mTORC1 and mTORC2 during the development of NK cells. Distribution of all five NK clusters along the pseudotime trajectory from the bone marrow of wild-type C57BL/6 mice. The relative maturity of the developmental trajectory is displayed across pseudotime. Distribution of each NK clusters along the pseudotime trajectory. Data presented are adapted from Yang et al., 2020.

and maturation (Townsend et al., 2004; Intlekofer et al., 2005; Gordon et al., 2012). Both contain highly conserved DNA-binding domains, indicating they bind to the same transcription factor-binding motifs. However, the interacting partners of Eomes and T-bet vary (Naiche et al., 2005; Zhang et al., 2018). IL-15 receptor, which activates the mTORC1 complex, plays an essential role in the early commitment and development of NK cells by promoting the transcription of E4BP4 (Kamizono et al., 2009). In turn, E4BP4 induces the expression of Id 2 and Eomes, two essential transcription factors for the early NK cell development (Yokota et al., 1999; Boos et al., 2007; Gordon et al., 2012; Male et al., 2014; Delconte et al., 2016). The single-cell transcriptomic profiles of NK cells from Rptor cKO mouse reveal that the iNK cell stage (CD27 single positive) failed to progress into the termNK cells (CD11b single positive). 
Reduced NK cell number in the periphery, reduced steady-state proliferation, and impaired migration in vitro demonstrate that the disruption of homeostatic NK cellularity is disrupted in Rptor cKO mice. Moreover, loss of mTORC1 significantly impaired NK cell maturation, as demonstrated by the accumulation of CD27 SP population and reduced DP and CD11b SP populations. This defect may directly contribute to the accumulation of NK cells in the BM, as they gradually obtain migratory capacity following CD11b expression (Mayol et al., 2011). Despite these findings, $\mathrm{Ncr} 1^{\mathrm{Cre}}$-mediated deletion of $P d p k 1$ or Tsc1 did not show any defects in NK cell development (Yang M. et al., 2015; Yang et al., 2016). This demonstrates that following Ncr1 expression, mTORC1 is activated through an alternative mechanism instead of the canonical PI(3)K-PDK1Akt-TSC1/2-mTORC1 pathway. mTORC1 regulates protein translation through various mechanisms. One of which directly affects the translation of proteins comprising the translational machinery such as eIFs, and ribosomal proteins (Meyuhas, 2000; Thoreen et al., 2012).

In contrast, mTORC1, lack of mTORC2 in Rictor $f / f l$ Ncrl ${ }^{\mathrm{Cre} / W T}$ mouse resulted in a blockade that did not allow CD27/CD11b double-positive NK cells to progress into terminally mature CD11b single-positive stage. scRNA-seq data demonstrate that in the absence of Rictor, NK cells possessed a high expression of upregulated genes of the iNK cluster, confirming this blockade (Figure 4). Importantly, lack of functional mTORC2 resulted in the significant upregulation of Forkhead transcription factors of the O class-1 (FoxO1). This family contains a winged-helix DNA-binding domain and the forkhead domain (Obsil and Obsilova, 2008). Earlier studies have shown that among the four members of this family (FoxO1, 3, 4, and 6), FoxO1 is highly expressed in NKPs and iNKs compare to mNKs. FoxO3 is expressed at all stages of NK cell development, albeit at a low level (Wang et al., 2016). Both FoxO1 and FoxO3 suppress the development of NK cells. Thus, mTORC2 performs a crucial function of suppressing the hyperactivation of FoxO1 (and potentially FoxO3a), via Akt-mediated phosphorylation and degradation of FoxO1, to allow the iNK cells to progress into the final maturation process. This function of mTORC2Akt-FoxO1 cascade is validated by the observation that both Ncr1-Cre -FoxO1 $1^{f l / f l}$ and -FoxO3 $3^{f l f l}$ mice possess much larger $\mathrm{CD} 27^{-} \mathrm{CD}_{11 \mathrm{~b}}{ }^{+} \mathrm{mNK}$, a moderately increased $\mathrm{CD} 27^{+} \mathrm{CD} 11 \mathrm{~b}^{+}$, and comparable $\mathrm{CD}_{2} 7^{+} \mathrm{CD} 11 \mathrm{~b}^{-}$iNK cell populations (Deng et al., 2015). Thus, the link between mTORC2 and FoxO1 is essential in the early stage of NK cell development. A higher expression of FoxO1 at the immature CD27 single-positive stage is to suppress any untoward expression of transcription factors responsible for the transition into mature NK cells. This is to safeguard an ordered process of gene expression and a faithfully executed NK cell maturation process. One of these transcription factors that is suppressed by FoxO1 is T-bet, which is essential for the terminal maturation and functions of NK cells (Townsend et al., 2004).

T-bet expression and protein levels progressively increase as the iNK cells advance into mature and termNK cells. Studies into the regulation of T-bet expression have provided exciting new insights about the interdependent cooperation and reciprocal suppression by Eomes or FoxO1 (Figure 4). FoxO1 exerts strong transcriptional repression on the $T b \times 21$ gene during the early NK cell maturation (Deng et al., 2015). While Runx3 (Levanon et al., 2014), E4bp4 (Male et al., 2014; Seillet et al., 2014), Ets-1 (Ramirez et al., 2012), and Tox2 (Vong et al., 2014) support the expression of Tbx21, FoxO1 interacts with Sp1 to bind to the Tbx21 proximal promoter to repress its transcription (Deng et al., 2015). Thus, apart from the positive regulation of Eomes by $\mathrm{mTORC1}$, the negative suppression by mTORC2 plays a crucial role in maintaining the gene signature of immature CD27 single positive NK cells. Further validation of this phenomenon is provided by our laboratory, where we reported that FoxO1 suppresses the transition of iNK to $\mathrm{mNK}$ cells through the axis of mTOR2-Akt ${ }^{S 43}$-FoxO1-T-bet (Yang et al., 2018). Also, FoxO1 suppresses the proliferation of developing NK cells by augmenting the transcription of genes that encode cell-cycle inhibitors (Deng et al., 2015). The continued interplay between FoxO1 and T-bet has been reported even after NK cells are fully matured (Deng et al., 2015). Activation of NK cells with IL-15, IL-2, or IL-12 resulted in the phosphorylation of FoxO1 at $\mathrm{Ser}^{256}$, resulting in its inability to be translocated into the nucleus and sequestrated into the cytoplasm for degradation. In concordance, loss of FoxO1 (Ncr1-Cre-FoxO1 ${ }^{f l / f l}$ ) increased anti-tumor cytotoxicity and the production of inflammatory cytokines, including IFN- $\gamma$ from NK cells (Deng et al., 2015).

Terminal maturation of NK cells requires Tsc1-dependent negative regulation of IL-15-triggered mTORC1 activation (Yang et al., 2016). IL-15R recruits and activates Jak1/3 that, in turn, phosphorylates and activates Stat $5 \mathrm{a} / \mathrm{b}$. Besides, activation receptors and IL-15R can initiate the $\mathrm{PI}(3) \mathrm{K}-\mathrm{p} 110 \delta / \mathrm{p} 85 \alpha$ in NK cells (Awasthi et al., 2008; Guo et al., 2008) to link mTORC1 to downstream signaling (Yang et al., 2016). In $\mathrm{CD}^{+} \mathrm{T}$ cells, Stat5a/b can initiate transcription of both T-bet and Eomes (Grange et al., 2013), and combined action of T-bet and Eomes at the Il2rb promoter region initiates the transcription IL-2R $\beta$ (CD122). The role of Stat5 in activating 4EBP1 has been postulated and thereby linking Stat5 to protein translation. However, an interplay between the IL15R-Jak1/2-Stat5a/b to IL-15R-PI(3)K-p1108/p85 $\alpha$-mTORC1 is not well-established. In this context, it is important to note that inhibitors of $\mathrm{PI}(3) \mathrm{K}-\mathrm{mTOR}$ pathway significantly reduced the phosphorylation of Stat5, demonstrating a potential link (Bartalucci et al., 2017). Other cytokine receptors such as IL$12 \mathrm{R}$ can also upregulate $\mathrm{T}$-bet expression primarily toward to production of IFN- $\gamma$ and the role of IL-12 during the development of NK cells is yet to be established (Klose et al., 2014; Zwirner and Ziblat, 2017).

Our recent work has unraveled a link between T-bet and FoxO1 downstream of mTORC2 (Figure 4). Lack of Rictor in NK cells resulted in augmented expression of FoxO1 and a significant decrease in the transcription of Tbx21. Congruently, lack of T-bet significantly augmented expression of FoxO1, indicating a reciprocal relationship between these two transcription factors. Importantly, the conditional deletion of FoxO1 in Rictordeficient mice resulted in the normal expression of T-bet and an increase in the number of termNK cells. These 


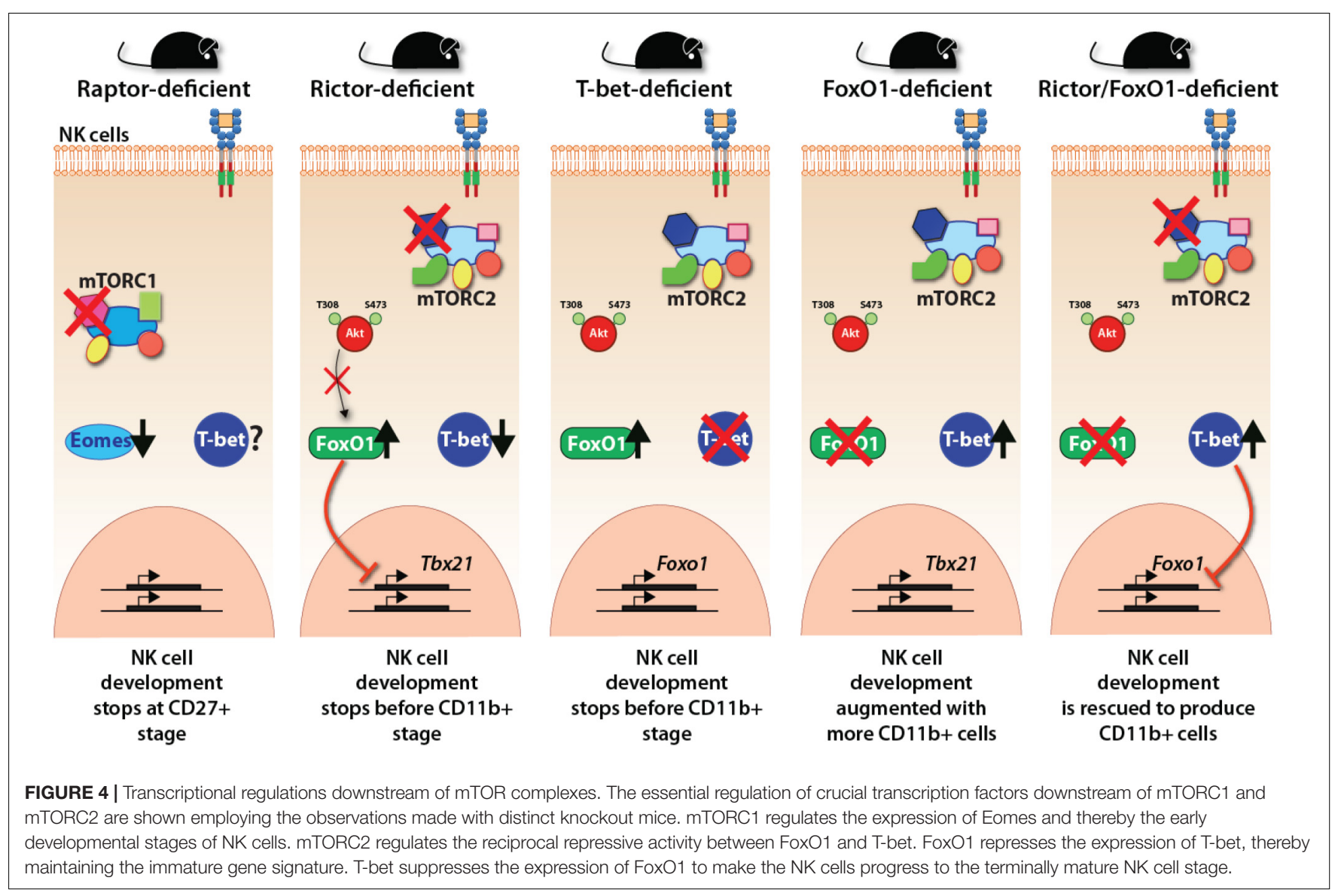

results were substantiated by the fact that T-bet-deficient mice largely phenocopied the developmental defects of NK cells in Rictor-deficient mice and the NK cells from FoxO1-deficient mice contained a significantly reduced level of T-bet. Thus, the suppression and degradation of FoxO1 by the mTORC2-Akt pathway is an essential mechanism for T-bet expression at the transitional stage 2 and 3 of NK cells allowing them to mature and functionally competent.

The ability of T-bet to directly bind to the intronic region and the regulatory region upstream of transcription starting site of Foxo1 locus strongly supports this notion. Thus, while the Foxo1, which has the highest expression in the CD27 SP subset (Deng et al., 2015), is essential for driving the expression of iNK signature genes, the activation via mTORC2 to shut down FoxO1 function to relieve the repression of T-bet is crucial for the final maturation process. The effector functions of NK cells depend on multiple transcription factors, including T-bet. The anti-tumor cytotoxicity and cytokine production are the major functions of mature NK cells. Lack of Rictor resulted in impaired anti-tumor functions of NK cells in vivo (Yang et al., 2018). Several transcription factors regulate the production of IFN- $\gamma$ and T-bet is one of the major regulators that directly binds to the ifng promoter and initiates its transcription (Beima et al., 2006; Miller et al., 2010). This involvement by the fact that T-bet-deficient NK cells have significantly reduced the ability to produce IFN- $\gamma$ (Townsend et al., 2004;
Gordon et al., 2012). Besides, T-bet-deficient NK cells do not sustain the production of IFN- $\gamma$ (Szabo et al., 2002; Townsend et al., 2004; Gordon et al., 2012). Also, T-bet can bind to Gzmb, prf1, and Runx1 promoter regions in NK cells (Townsend et al., 2004; Gordon et al., 2012). T-bet-deficient NK cells are impaired in their anti-tumor effector functions (Townsend et al., 2004; Intlekofer et al., 2005; Gordon et al., 2012). Thus, mTORC2 plays an integral role in NK cell-mediated effector functions.

\section{SUMMARY AND FUTURE OUTLOOK}

Mechanistic target of Rapamycin complexes play an essential and complex role in the development and functions of $\mathrm{NK}$ cells. The mechanism they utilize to regulate the metabolic reprogramming and transcriptional regulation in NK cells hold promise in identifying novel molecular targets to formulate better immunotherapies. Advanced technologies, including single-cell RNA sequencing, are allowing us to define these mechanisms downstream of mTORC1 and mTORC2. The transcriptional regulations mediated by these complexes are emerging. A novel new pathway via the mTORC2-Akt ${ }^{S 473}$ FoxO1-T-bet axis regulates the expression of iNK genes during NK cell development. mTORC1-Eomes pathway downstream of IL-15 regulates the early developmental stages of NK cells, 
while an mTORC2-Akt ${ }^{S 43}$-FoxO1-T-bet pathway is critical for the terminal maturation of NK cells. Reciprocal activation or repression of Eomes/T-bet and FoxO1/T-bet are two major examples of how mTOR complexes coordinate a complex gene transcription process to mature NK cells. Irrespective of this progress, critical questions remain open. What are the independent roles of mTORC1 and MTORC2 in distinct stages of NK cell development? What roles do mTORC2 play in IL-15mediated NK cell priming? Are mTORC1 and mTORC2 essential for the downstream signaling of activating receptors? Answers to these questions will help better define the unique roles played by mTOR complexes in human NK cells and help in targeting novel signaling proteins for therapeutic purposes.

\section{REFERENCES}

Alessi, D. R., James, S. R., Downes, C. P., Holmes, A. B., Gaffney, P. R., Reese, C. B., et al. (1997). Characterization of a 3-phosphoinositide-dependent protein kinase which phosphorylates and activates protein kinase Balpha. Curr. Biol. 7, 261-269. doi: 10.1016/s0960-9822(06)00122-9

Alessi, D. R., Kozlowski, M. T., Weng, Q. P., Morrice, N., and Avruch, J. (1998). 3-Phosphoinositide-dependent protein kinase 1 (PDK1) phosphorylates and activates the p70 S6 kinase in vivo and in vitro. Curr. Biol. 8, 69-81. doi: 10.1016/s0960-9822(98)70037-5

Awasthi, A., Samarakoon, A., Dai, X., Wen, R., Wang, D., and Malarkannan, S. (2008). Deletion of PI3K-p85alpha gene impairs lineage commitment, terminal maturation, cytokine generation and cytotoxicity of NK cells. Genes Immun. 9, 522-535. doi: 10.1038/gene.2008.45

Aylett, C. H., Sauer, E., Imseng, S., Boehringer, D., Hall, M. N., Ban, N., et al. (2016). Architecture of human mTOR complex 1. Science 351, 48-52.

Bamford, R. N., Grant, A. J., Burton, J. D., Peters, C., Kurys, G., Goldman, C. K., et al. (1994). The interleukin (IL) 2 receptor beta chain is shared by IL-2 and a cytokine, provisionally designated IL-T, that stimulates T-cell proliferation and the induction of lymphokine-activated killer cells. Proc. Natl. Acad. Sci. U S A. 91, 4940-4944. doi: 10.1073/pnas.91.11.4940

Baretic, D., Berndt, A., Ohashi, Y., Johnson, C. M., and Williams, R. L. (2016). Tor forms a dimer through an N-terminal helical solenoid with a complex topology. Nat. Commun. 7:11016.

Bartalucci, N., Calabresi, L., Balliu, M., Martinelli, S., Rossi, M. C., Villeval, J. L., et al. (2017). Inhibitors of the PI3K/mTOR pathway prevent STAT5 phosphorylation in JAK2V617F mutated cells through PP2A/CIP2A axis. Oncotarget 8, 96710-96724. doi: 10.18632/oncotarget.18073

Becknell, B., and Caligiuri, M. A. (2005). Interleukin-2, interleukin-15, and their roles in human natural killer cells. Adv. Immunol. 86, 209-239. doi: 10.1016/ s0065-2776(04)86006-1

Beima, K. M., Miazgowicz, M. M., Lewis, M. D., Yan, P. S., Huang, T. H., and Weinmann, A. S. (2006). T-bet binding to newly identified target gene promoters is cell type-independent but results in variable contextdependent functional effects. J. Biol. Chem. 281, 11992-12000. doi: 10.1074/jbc. m513613200

Ben-Sahra, I., Howell, J. J., Asara, J. M., and Manning, B. D. (2013). Stimulation of de novo pyrimidine synthesis by growth signaling through mTOR and S6K1. Science 339, 1323-1328. doi: 10.1126/science. 1228792

Ben-Sahra, I., Hoxhaj, G., Ricoult, S. J. H., Asara, J. M., and Manning, B. D. (2016). mTORC1 induces purine synthesis through control of the mitochondrial tetrahydrofolate cycle. Science 351, 728-733. doi: 10.1126/science.aad0489

Boos, M. D., Yokota, Y., Eberl, G., and Kee, B. L. (2007). Mature natural killer cell and lymphoid tissue-inducing cell development requires Id2-mediated suppression of E protein activity. J. Exp. Med. 204, 1119-1130. doi: 10.1084/ jem.20061959

Boulanger, M. J., and Garcia, K. C. (2004). Shared cytokine signaling receptors: structural insights from the gp130 system. Adv. Prot. Chem. 68, 107-146. doi: 10.1016/s0065-3233(04)68004- 1

\section{AUTHOR CONTRIBUTIONS}

$\mathrm{CY}$ conceived, wrote the manuscript, and generated the figures. SM conceived, wrote, and generated the manuscript, supervised the work, and obtained funding for the work. All authors contributed to the article and approved the submitted version.

\section{FUNDING}

This work was supported in part by NIH R01 AI102893 and NCI R01 CA179363 (SM); HRHM Program of MACC Fund (SM), Nicholas Family Foundation (SM); and Gardetto Family (SM).

Boussiotis, V. A., Barber, D. L., Nakarai, T., Freeman, G. J., Gribben, J. G., and Bernstein, G. M. (1994). Prevention of T cell anergy by signaling through the gamma c chain of the IL-2 receptor. Science 266, 1039-1042. doi: 10.1126/ science.7973657

Boyman, O., and Sprent, J. (2012). The role of interleukin-2 during homeostasis and activation of the immune system. Nat. Rev. Immunol. 12, 180-190. doi: $10.1038 /$ nri3156

Brown, E. J., Albers, M. W., Shin, T. B., Ichikawa, K., Keith, C. T., Lane, W. S., et al. (1994). A mammalian protein targeted by G1-arresting rapamycin-receptor complex. Nature 369, 756-758. doi: 10.1038/369756a0

Brunn, G. J., Hudson, C. C., Sekulic, A., Williams, J. M., Hosoi, H., Houghton, P. J., et al. (1997). Phosphorylation of the translational repressor PHAS-I by the mammalian target of rapamycin. Science 277, 99-101. doi: 10.1126/science.277. 5322.99

Chung, J., Kuo, C. J., Crabtree, G. R., and Blenis, J. (1992). Rapamycin-FKBP specifically blocks growth-dependent activation of and signaling by the 70 kd S6 protein kinases. Cell 69, 1227-1236. doi: 10.1016/0092-8674(92)90 643-q

Cong, J., Wang, X., Zheng, X., Wang, D., Fu, B., Sun, R., et al. (2018). Dysfunction of Natural Killer Cells by FBP1-Induced Inhibition of Glycolysis during Lung Cancer Progression. Cell Metab.24, 243-255.e5.

Crinier, A., Milpied, P., Escaliere, B., Piperoglou, C., Galluso, J., and Balsamo, A. (2018). High-Dimensional Single-Cell Analysis Identifies Organ-Specific Signatures and Conserved NK Cell Subsets in Humans and Mice. Immunity. 49, 971-986.e5.

Delconte, R. B., Shi, W., Sathe, P., Ushiki, T., Seillet, C., Minnich, M., et al. (2016). The Helix-Loop-Helix Protein ID2 Governs NK Cell Fate by Tuning Their Sensitivity to Interleukin-15. Immunity 44, 103-115. doi: 10.1016/j.immuni. 2015.12.007

Deng, Y., Kerdiles, Y., Chu, J., Yuan, S., Wang, Y., Chen, X., et al. (2015). Transcription factor Foxo1 is a negative regulator of natural killer cell maturation and function. Immunity 42, 457-470. doi: 10.1016/j.immuni.2015. 02.006

Dibble, C. C., Elis, W., Menon, S., Qin, W., Klekota, J., Asara, J. M., et al. (2012). TBC1D7 is a third subunit of the TSC1-TSC2 complex upstream of mTORC1. Mol. Cell 47, 535-546. doi: 10.1016/j.molcel.2012.06.009

DiSanto, J. P., Muller, W., Guy-Grand, D., Fischer, A., and Rajewsky, K. (1995). Lymphoid development in mice with a targeted deletion of the interleukin 2 receptor gamma chain. Proc. Natl. Acad. Sci. U S A 92, 377-381. doi: 10.1073/ pnas.92.2.377

Dogra, P., Rancan, C., Ma, W., Toth, M., Senda, T., and Carpenter, D. J. (2020). Tissue Determinants of Human NK Cell Development, Function, and Residence. Cell 180, 749-763e13.

Donnelly, R. P., Loftus, R. M., Keating, S. E., Liou, K. T., Biron, C. A., Gardiner, C. M., et al. (2014). mTORC1-dependent metabolic reprogramming is a prerequisite for NK cell effector function. J. Immunol. 193, 4477-4484. doi: 10.4049/jimmunol.1401558

Dorrello, N. V., Peschiaroli, A., Guardavaccaro, D., Colburn, N. H., Sherman, N. E., and Pagano, M. (2006). S6K1- and betaTRCP-mediated degradation of 
PDCD4 promotes protein translation and cell growth. Science 314, 467-471. doi: 10.1126/science.1130276

Dubois, S., Mariner, J., Waldmann, T. A., and Tagaya, Y. (2002). IL-15Ralpha recycles and presents IL-15 In trans to neighboring cells. Immunity 17, 537-547. doi: 10.1016/s1074-7613(02)00429-6

Duvel, K., Yecies, J. L., Menon, S., Raman, P., Lipovsky, A. I., Souza, A. L., et al. (2010). Activation of a metabolic gene regulatory network downstream of mTOR complex 1. Mol. Cell 39, 171-183. doi: 10.1016/j.molcel.2010.06.022

Eckelhart, E., Warsch, W., Zebedin, E., Simma, O., Stoiber, D., Kolbe, T., et al. (2011). A novel Ncr1-Cre mouse reveals the essential role of STAT5 for NK-cell survival and development. Blood 117, 1565-1573. doi: 10.1182/blood-2010-06291633

Eng, C. P., Sehgal, S. N., and Vezina, C. (1984). Activity of rapamycin (AY22,989) against transplanted tumors. J. Antibiot. 37, 1231-1237. doi: 10.7164/ antibiotics.37.1231

Frias, M. A., Thoreen, C. C., Jaffe, J. D., Schroder, W., Sculley, T., Carr, S. A., et al. (2006). mSin 1 is necessary for Akt/PKB phosphorylation, and its isoforms define three distinct mTORC2s. Curr. Biol. 16, 1865-1870.

Fujii, H., Ogasawara, K., Otsuka, H., Suzuki, M., Yamamura, K., Yokochi, T., et al. (1998). Functional dissection of the cytoplasmic subregions of the IL-2 receptor betac chain in primary lymphocyte populations. EMBO J. 17, 6551-6557. doi: 10.1093/emboj/17.22.6551

Gan, X., Wang, J., Wang, C., Sommer, E., Kozasa, T., Srinivasula, S., et al. (2012). PRR5L degradation promotes mTORC2-mediated PKC-delta phosphorylation and cell migration downstream of Galpha12. Nat. Cell Biol. 14, 686-696. doi: $10.1038 /$ ncb2507

Gingras, A. C., Gygi, S. P., Raught, B., Polakiewicz, R. D., Abraham, R. T., Hoekstra, M. F., et al. (1999). Regulation of 4E-BP1 phosphorylation: a novel two-step mechanism. Genes Dev. 13, 1422-1437. doi: 10.1101/gad.13.11.1422

Giri, J. G., Ahdieh, M., Eisenman, J., Shanebeck, K., Grabstein, K., Kumaki, S., et al. (1994). Utilization of the beta and gamma chains of the IL-2 receptor by the novel cytokine IL-15. EMBO J. 13, 2822-2830. doi: 10.1002/j.1460-2075.1994. tb06576.x

Giri, J. G., Kumaki, S., Ahdieh, M., Friend, D. J., Loomis, A., Shanebeck, K., et al. (1995). Identification and cloning of a novel IL-15 binding protein that is structurally related to the alpha chain of the IL-2 receptor. $E M B O \mathrm{~J} .14$, 3654-3663. doi: 10.1002/j.1460-2075.1995.tb00035.x

Gordon, S. M., Chaix, J., Rupp, L. J., Wu, J., Madera, S., Sun, J. C., et al. (2012). The transcription factors T-bet and Eomes control key checkpoints of natural killer cell maturation. Immunity 36, 55-67. doi: 10.1016/j.immuni.2011. 11.016

Grabstein, K. H., Eisenman, J., Shanebeck, K., Rauch, C., Srinivasan, S., Fung, V., et al. (1994). Cloning of a T cell growth factor that interacts with the beta chain of the interleukin-2 receptor. Science 264, 965-968. doi: 10.1126/science. 8178155

Grange, M., Verdeil, G., Arnoux, F., Griffon, A., Spicuglia, S., Maurizio, J., et al. (2013). Active STAT5 regulates T-bet and eomesodermin expression in CD8 T cells and imprints a T-bet-dependent Tcl program with repressed IL-6/TGFbeta1 signaling. J. Immunol. 191, 3712-3724. doi: 10.4049/jimmunol.1300319

Guertin, D. A., Stevens, D. M., Thoreen, C. C., Burds, A. A., Kalaany, N. Y., Moffat, J., et al. (2006). Ablation in mice of the mTORC components raptor, rictor, or mLST8 reveals that mTORC2 is required for signaling to Akt-FOXO and PKCalpha, but not S6K1. Dev. Cell 11, 859-871. doi: 10.1016/j.devcel.2006. 10.007

Guo, H., Samarakoon, A., Vanhaesebroeck, B., and Malarkannan, S. (2008). The p110 delta of PI3K plays a critical role in NK cell terminal maturation and cytokine/chemokine generation. J. Exp. Med. 205, 2419-2435. doi: 10.1084/jem. 20072327

Gwinn, D. M., Shackelford, D. B., Egan, D. F., Mihaylova, M. M., Mery, A., Vasquez, D. S., et al. (2008). AMPK phosphorylation of raptor mediates a metabolic checkpoint. Mol. Cell 30, 214-226. doi: 10.1016/j.molcel.2008.03.003

Habif, G., Crinier, A., Andre, P., Vivier, E., and Narni-Mancinelli, E. (2019). Targeting natural killer cells in solid tumors. Cell Mol. Immunol. 16, 415-422. doi: 10.1038/s41423-019-0224-2

Hara, K., Maruki, Y., Long, X., Yoshino, K., Oshiro, N., Hidayat, S., et al. (2002). Raptor, a binding partner of target of rapamycin (TOR), mediates TOR action. Cell 110, 177-189. doi: 10.1016/s0092-8674(02)00833-4
Harrington, L. S., Findlay, G. M., Gray, A., Tolkacheva, T., Wigfield, S., Rebholz, H., et al. (2004). The TSC1-2 tumor suppressor controls insulin-PI3K signaling via regulation of IRS proteins. J. Cell Biol. 166, 213-223. doi: 10.1083/jcb.200403069 Hill, M. M., Andjelkovic, M., Brazil, D. P., Ferrari, S., Fabbro, D., and Hemmings, B. A. (2001). Insulin-stimulated protein kinase B phosphorylation on Ser-473 is independent of its activity and occurs through a staurosporine-insensitive kinase. J. Biol. Chem. 276, 25643-25646. doi: 10.1074/jbc.c100174200

Holz, M. K., Ballif, B. A., Gygi, S. P., and Blenis, J. (2005). mTOR and S6K1 mediate assembly of the translation preinitiation complex through dynamic protein interchange and ordered phosphorylation events. Cell 123, 569-580. doi: 10.1016/j.cell.2005.10.024

Hsu, P. P., Kang, S. A., Rameseder, J., Zhang, Y., Ottina, K. A., Lim, D., et al. (2011). The mTOR-regulated phosphoproteome reveals a mechanism of mTORC1mediated inhibition of growth factor signaling. Science 332, 1317-1322. doi: 10.1126/science. 1199498

Imada, K., Bloom, E. T., Nakajima, H., Horvath-Arcidiacono, J. A., Udy, G. B., Davey, H. W., et al. (1998). Stat5b is essential for natural killer cell-mediated proliferation and cytolytic activity. J. Exp. Med. 188, 2067-2074. doi: 10.1084/ jem.188.11.2067

Inoki, K., Li, Y., Zhu, T., Wu, J., and Guan, K. L. (2002). TSC2 is phosphorylated and inhibited by Akt and suppresses mTOR signalling. Nat. Cell Biol. 4, 648-657. doi: 10.1038/ncb839

Inoki, K., Zhu, T., and Guan, K. L. (2003). TSC2 mediates cellular energy response to control cell growth and survival. Cell 115, 577-590. doi: 10.1016/s00928674(03)00929-2

Intlekofer, A. M., Takemoto, N., Wherry, E. J., Longworth, S. A., Northrup, J. T., Palanivel, V. R., et al. (2005). Effector and memory CD8 + T cell fate coupled by T-bet and eomesodermin. Nat. Immunol. 6, 1236-1244. doi: 10.1038/nil268

Jacinto, E., Facchinetti, V., Liu, D., Soto, N., Wei, S., Jung, S. Y., et al. (2006). SIN1/MIP1 maintains rictor-mTOR complex integrity and regulates Akt phosphorylation and substrate specificity. Cell 127, 125-137. doi: 10.1016/j.cell. 2006.08.033

Jacinto, E., Loewith, R., Schmidt, A., Lin, S., Ruegg, M. A., Hall, A., et al. (2004). complex 2 controls the actin cytoskeleton and is rapamycin insensitive. Nat. Cell Biol. 6, 1122-1128. doi: 10.1038/ncb1183

Kalender, A., Selvaraj, A., Kim, S. Y., Gulati, P., Brule, S., Viollet, B., et al (2010). Metformin, independent of AMPK, inhibits mTORC1 in a rag GTPasedependent manner. Cell Metab. 11, 390-401. doi: 10.1016/j.cmet.2010.03.014

Kamizono, S., Duncan, G. S., Seidel, M. G., Morimoto, A., Hamada, K., Grosveld, G., et al. (2009). Nfil3/E4bp4 is required for the development and maturation of NK cells in vivo. J. Exp. Med. 206, 2977-2986. doi: 10.1084/jem.20092176

Kennedy, M. K., Glaccum, M., Brown, S. N., Butz, E. A., Viney, J. L., Embers, M., et al. (2000). Reversible defects in natural killer and memory CD8 T cell lineages in interleukin 15-deficient mice. J. Exp. Med. 191, 771-780. doi: 10.1084/jem. 191.5.771

Kim, D. H., Sarbassov, D. D., Ali, S. M., King, J. E., Latek, R. R., ErdjumentBromage, H., et al. (2002). mTOR interacts with raptor to form a nutrientsensitive complex that signals to the cell growth machinery. Cell 110, 163-175. doi: 10.1016/s0092-8674(02)00808-5

Kim, E., Goraksha-Hicks, P., Li, L., Neufeld, T. P., and Guan, K. L. (2008). Regulation of TORC1 by Rag GTPases in nutrient response. Nat. Cell Biol. 10, 935-945. doi: 10.1038/ncb1753

Kim, N., Saudemont, A., Webb, L., Camps, M., Ruckle, T., Hirsch, E., et al. (2007). The p110delta catalytic isoform of PI3K is a key player in NK-cell development and cytokine secretion. Blood 110, 3202-3208. doi: 10.1182/blood-2007-02075366

Klose, C. S., Blatz, K., d'Hargues, Y., Hernandez, P. P., Kofoed-Nielsen, M., Ripka, J. F., et al. (2014). . Immunity 41, 230-243.

Kondo, M., Weissman, I. L., and Akashi, K. (1997). Identification of clonogenic common lymphoid progenitors in mouse bone marrow. Cell 91, 661-672. doi: 10.1016/s0092-8674(00)80453-5

Kuo, C. J., Chung, J., Fiorentino, D. F., Flanagan, W. M., Blenis, J., and Crabtree, G. R. (1992). Rapamycin selectively inhibits interleukin-2 activation of p70 S6 kinase. Nature 358, 70-73. doi: 10.1038/358070a0

Levanon, D., Negreanu, V., Lotem, J., Bone, K. R., Brenner, O., Leshkowitz, D., et al. (2014). Transcription factor Runx3 regulates interleukin-15-dependent natural killer cell activation. Mol. Cell Biol. 34, 1158-1169. doi: 10.1128/mcb.01202-13 
Li, X., and Gao, T. (2014). mTORC2 phosphorylates protein kinase Czeta to regulate its stability and activity. EMBO Rep. 15, 191-198. doi: 10.1002/embr. 201338119

Liu, P., Gan, W., Chin, Y. R., Ogura, K., Guo, J., Zhang, J., et al. (2015). PtdIns(3,4,5)P3-Dependent Activation of the mTORC2 Kinase Complex. Cancer Discov. 5, 1194-1209. doi: 10.1158/2159-8290.cd-15-0460

Lodolce, J. P., Boone, D. L., Chai, S., Swain, R. E., Dassopoulos, T., Trettin, S., et al. (1998). IL-15 receptor maintains lymphoid homeostasis by supporting lymphocyte homing and proliferation. Immunity 9, 669-676. doi: 10.1016/ s1074-7613(00)80664-0

Long, X., Lin, Y., Ortiz-Vega, S., Yonezawa, K., and Avruch, J. (2005). Rheb binds and regulates the mTOR kinase. Curr. Biol. 15, 702-713. doi: 10.1016/j.cub. 2005.02.053

Ma, L., Chen, Z., Erdjument-Bromage, H., Tempst, P., and Pandolfi, P. P. (2005). Phosphorylation and functional inactivation of TSC2 by Erk implications for tuberous sclerosis and cancer pathogenesis. Cell 121, 179-193. doi: 10.1016/j. cell.2005.02.031

Mah, A. Y., Rashidi, A., Keppel, M. P., Saucier, N., Moore, E. K., Alinger, J. B., et al. (2017). Glycolytic requirement for NK cell cytotoxicity and cytomegalovirus control. JCI Insight 2:e95128.

Male, V., Nisoli, I., Kostrzewski, T., Allan, D. S., Carlyle, J. R., Lord, G. M., et al. (2014). The transcription factor E4bp4/Nfil3 controls commitment to the NK lineage and directly regulates Eomes and Id2 expression. J. Exp. Med. 211, 635-642. doi: 10.1084/jem.20132398

Manning, B. D., Tee, A. R., Logsdon, M. N., Blenis, J., and Cantley, L. C. (2002). Identification of the tuberous sclerosis complex-2 tumor suppressor gene product tuberin as a target of the phosphoinositide 3-kinase/akt pathway. Mol. Cell 10, 151-162. doi: 10.1016/s1097-2765(02)00568-3

Marcais, A., and Walzer, T. (2014). mTOR: a gate to NK cell maturation and activation. Cell Cycle 13, 3315-3316. doi: 10.4161/15384101.2014.972919

Marcais, A., Cherfils-Vicini, J., Viant, C., Degouve, S., Viel, S., Fenis, A., et al. (2014). The metabolic checkpoint kinase mTOR is essential for IL-15 signaling during the development and activation of NK cells. Nat. Immunol. 15, 749-757. doi: $10.1038 /$ ni.2936

Marcais, A., Marotel, M., Degouve, S., Koenig, A., Fauteux-Daniel, S., Drouillard, A., et al. (2017). High mTOR activity is a hallmark of reactive natural killer cells and amplifies early signaling through activating receptors. Elife 6:e26423.

Marcais, A., Viel, S., Grau, M., Henry, T., Marvel, J., and Walzer, T. (2013). Regulation of mouse NK cell development and function by cytokines. Front. Immunol. 4:450. doi: 10.3389/fimmu.2013.00450

Martel, R. R., Klicius, J., and Galet, S. (1977). Inhibition of the immune response by rapamycin, a new antifungal antibiotic. Can. J. Physiol. Pharmacol. 55, 48-51. doi: 10.1139/y77-007

Mayol, K., Biajoux, V., Marvel, J., Balabanian, K., and Walzer, T. (2011). Sequential desensitization of CXCR4 and S1P5 controls natural killer cell trafficking. Blood 118, 4863-4871. doi: 10.1182/blood-2011-06-362574

Menon, S., Dibble, C. C., Talbott, G., Hoxhaj, G., Valvezan, A. J., Takahashi, H., et al. (2014). Spatial control of the TSC complex integrates insulin and nutrient regulation of mTORC1 at the lysosome. Cell 156, 771-785. doi: 10.1016/j.cell. 2013.11.049

Merrick, W. C. (2004). Cap-dependent and cap-independent translation in eukaryotic systems. Gene 332, 1-11. doi: 10.1016/j.gene.2004.02.051

Meyuhas, O. (2000). Synthesis of the translational apparatus is regulated at the translational level. Eur. J. Biochem. 267, 6321-6330. doi: 10.1046/j.1432-1327. 2000.01719.x

Miller, S. A., Mohn, S. E., and Weinmann, A. S. (2010). Jmjd3 and UTX play a demethylase-independent role in chromatin remodeling to regulate T-box family member-dependent gene expression. Mol. Cell 40, 594-605. doi: 10.1016/ j.molcel.2010.10.028

Miyazaki, T., Kawahara, A., Fujii, H., Nakagawa, Y., Minami, Y., Liu, Z. J., et al. (1994). Functional activation of Jak1 and Jak3 by selective association with IL-2 receptor subunits. Science 266, 1045-1047. doi: 10.1126/science.7973659

Morita, M., Prudent, J., Basu, K., Goyon, V., Katsumura, S., and Hulea, L. (2017). mTOR Controls Mitochondrial Dynamics and Cell Survival via MTFP1. Mol. Cell. 67, 922-935.e5.

Mortier, E., Woo, T., Advincula, R., Gozalo, S., and Ma, A. (2008). IL-15Ralpha chaperones IL-15 to stable dendritic cell membrane complexes that activate
NK cells via trans presentation. J. Exp. Med. 205, 1213-1225. doi: 10.1084/jem. 20071913

Muller-Durovic, B., Lanna, A., Covre, L. P., Mills, R. S., Henson, S. M., and Akbar, A. N. (2016). Killer Cell Lectin-like Receptor G1 Inhibits NK Cell Function through Activation of Adenosine 5'-Monophosphate-Activated Protein Kinase. J. Immunol. 197, 2891-2899. doi: 10.4049/jimmunol.1600590

Naiche, L. A., Harrelson, Z., Kelly, R. G., and Papaioannou, V. E. (2005). T-box genes in vertebrate development. Annu. Rev. Genet 39, 219-239. doi: 10.1146/ annurev.genet.39.073003.105925

Nandagopal, N., Ali, A. K., Komal, A. K., and Lee, S. H. (2014). The Critical Role of IL-15-PI3K-mTOR Pathway in Natural Killer Cell Effector Functions. Front. Immunol. 5:187. doi: 10.3389/fimmu.2014.00187

Noguchi, M., Yi, H., Rosenblatt, H. M., Filipovich, A. H., Adelstein, S., Modi, W. S., et al. (1993). Interleukin-2 receptor gamma chain mutation results in X-linked severe combined immunodeficiency in humans. Cell 73, 147-157. doi: 10.1016/0092-8674(93)90167-o

Obsil, T., and Obsilova, V. (2008). Structure/function relationships underlying regulation of FOXO transcription factors. Oncogene 27, 2263-2275. doi: 10. 1038 /onc. 2008.20

Okkenhaug, K. (2013). Signaling by the phosphoinositide 3-kinase family in immune cells. Annu. Rev. Immunol. 31, 675-704. doi: 10.1146/annurevimmunol-032712-095946

Park, S. Y., Saijo, K., Takahashi, T., Osawa, M., Arase, H., Hirayama, N., et al. (1995). Developmental defects of lymphoid cells in Jak3 kinase-deficient mice. Immunity 3, 771-782. doi: 10.1016/1074-7613(95)90066-7

Pearson, R. B., Dennis, P. B., Han, J. W., Williamson, N. A., Kozma, S. C., Wettenhall, R. E., et al. (1995). The principal target of rapamycin-induced p70s6k inactivation is a novel phosphorylation site within a conserved hydrophobic domain. EMBO J. 14, 5279-5287. doi: 10.1002/j.1460-2075.1995. tb00212.x

Peterson, T. R., Sengupta, S. S., Harris, T. E., Carmack, A. E., Kang, S. A., Balderas, E., et al. (2011). mTOR complex 1 regulates lipin 1 localization to control the SREBP pathway. Cell 146, 408-420. doi: 10.1016/j.cell.2011.06.034

Pullen, N., Dennis, P. B., Andjelkovic, M., Dufner, A., Kozma, S. C., Hemmings, B. A., et al. (1998). Phosphorylation and activation of p70s6k by PDK1. Science 279, 707-710. doi: 10.1126/science.279.5351.707

Ramirez, K., Chandler, K. J., Spaulding, C., Zandi, S., Sigvardsson, M., Graves, B. J., et al. (2012). Gene deregulation and chronic activation in natural killer cells deficient in the transcription factor ETS1. Immunity 36, 921-932. doi: 10.1016/j.immuni.2012.04.006

Richter, J. D., and Sonenberg, N. (2005). Regulation of cap-dependent translation by eIF4E inhibitory proteins. Nature 433, 477-480. doi: 10.1038/nature03205

Rickert, M., Wang, X., Boulanger, M. J., Goriatcheva, N., and Garcia, K. C. (2005). The structure of interleukin-2 complexed with its alpha receptor. Science 308, 1477-1480. doi: 10.1126/science. 1109745

Robitaille, A. M., Christen, S., Shimobayashi, M., Cornu, M., Fava, L. L., Moes, S., et al. (2013). Quantitative phosphoproteomics reveal mTORC1 activates de novo pyrimidine synthesis. Science 339, 1320-1323. doi: 10.1126/science. 1228771

Rosmaraki, E. E., Douagi, I., Roth, C., Colucci, F., Cumano, A., and Di Santo, J. P. (2001). Identification of committed NK cell progenitors in adult murine bone marrow. Eur. J. Immunol. 31, 1900-1909. doi: 10.1002/1521-4141(200106)31: $6<1900::$ aid-immu1900>3.0.co;2-m

Roux, P. P., Ballif, B. A., Anjum, R., Gygi, S. P., and Blenis, J. (2004). Tumorpromoting phorbol esters and activated Ras inactivate the tuberous sclerosis tumor suppressor complex via p90 ribosomal S6 kinase. Proc. Natl. Acad. Sci. U S A 101, 13489-13494. doi: 10.1073/pnas.0405659101

Russell, S. M., Johnston, J. A., Noguchi, M., Kawamura, M., Bacon, C. M., Friedmann, M., et al. (1994). Interaction of IL-2R beta and gamma c chains with Jak1 and Jak3: implications for XSCID and XCID. Science 266, 1042-1045. doi: $10.1126 /$ science. 7973658

Sabatini, D.M. (2017). Twenty-five years of mTOR: Uncovering the link from nutrients to growth. Proc. Natl. Acad. Sci. U S A. 114:201716173.

Sabatini, D. M., Erdjument-Bromage, H., Lui, M., Tempst, P., and Snyder, S. H. (1994). RAFT1: a mammalian protein that binds to FKBP12 in a rapamycindependent fashion and is homologous to yeast TORs. Cell 78, 35-43. doi: 10.1016/0092-8674(94)90570-3 
Sabers, C. J., Martin, M. M., Brunn, G. J., Williams, J. M., Dumont, F. J., Wiederrecht, G., et al. (1995). Isolation of a protein target of the FKBP12rapamycin complex in mammalian cells. J. Biol. Chem. 270, 815-822. doi: $10.1074 /$ jbc. 270.2 .815

Sancak, Y., Peterson, T. R., Shaul, Y. D., Lindquist, R. A., Thoreen, C. C., Bar-Peled, L., et al. (2008). The Rag GTPases bind raptor and mediate amino acid signaling to mTORC1. Science 320, 1496-1501. doi: 10.1126/science.1157535

Sarbassov, D. D., Ali, S. M., Kim, D. H., Guertin, D. A., Latek, R. R., ErdjumentBromage, H., et al. (2004). Rictor, a novel binding partner of mTOR, defines a rapamycin-insensitive and raptor-independent pathway that regulates the cytoskeleton. Curr. Biol. 14, 1296-1302. doi: 10.1016/j.cub.2004.06.054

Sarbassov, D. D., Ali, S. M., Sengupta, S., Sheen, J. H., Hsu, P. P., Bagley, A. F., et al. (2006). Prolonged rapamycin treatment inhibits mTORC2 assembly and Akt/PKB. Mol. Cell 22, 159-168. doi: 10.1016/j.molcel.2006.03.029

Sarbassov, D. D., Guertin, D. A., Ali, S. M., and Sabatini, D. M. (2005). Phosphorylation and regulation of $\mathrm{Akt} / \mathrm{PKB}$ by the rictor-mTOR complex. Science 307, 1098-1101. doi: 10.1126/science.1106148

Saxton, R. A., and Sabatini, D. M. (2017). mTOR Signaling in Growth, Metabolism, and Disease. Cell 169, 361-371. doi: 10.1016/j.cell.2017.03.035

Schroder, W. A., Buck, M., Cloonan, N., Hancock, J. F., Suhrbier, A., Sculley, T., et al. (2007). Human Sin 1 contains Ras-binding and pleckstrin homology domains and suppresses Ras signalling. Cell Sign. 19, 1279-1289. doi: 10.1016/j. cellsig.2007.01.013

Schroder, W., Cloonan, N., Bushell, G., and Sculley, T. (2004). Alternative polyadenylation and splicing of mRNAs transcribed from the human Sin 1 gene. Gene 339, 17-23. doi: 10.1016/j.gene.2004.07.001

Sehgal, S. N., Baker, H., and Vezina, C. (1975). Rapamycin (AY-22,989), a new antifungal antibiotic. IFermentation, I., isolation and characterization. J. Antibiot. 28, 727-732. doi: 10.7164/antibiotics.28.727

Seillet, C., Huntington, N. D., Gangatirkar, P., Axelsson, E., Minnich, M., Brady, H. J., et al. (2014). Differential requirement for Nfil3 during NK cell development. J. Immunol. 192, 2667-2676. doi: 10.4049/jimmunol.1302605

Shah, O. J., Wang, Z., and Hunter, T. (2004). Inappropriate activation of the TSC/Rheb/mTOR/S6K cassette induces IRS1/2 depletion, insulin resistance, and cell survival deficiencies. Curr. Biol. 14, 1650-1656. doi: 10.1016/j.cub.2004. 08.026

Shaw, R. J., Bardeesy, N., Manning, B. D., Lopez, L., Kosmatka, M., DePinho, R. A., et al. (2004). The LKB1 tumor suppressor negatively regulates mTOR signaling. Cancer Cell 6, 91-99. doi: 10.1016/j.ccr.2004.06.007

Stauber, D. J., Debler, E. W., Horton, P. A., Smith, K. A., and Wilson, I. A. (2006). Crystal structure of the IL-2 signaling complex: paradigm for a heterotrimeric cytokine receptor. Proc. Natl. Acad. Sci. U S A. 103, 2788-2793. doi: 10.1073/ pnas.0511161103

Summer, R., Shaghaghi, H., Schriner, D., Roque, W., Sales, D., and Cuevas-Mora, K. (2019). Activation of the mTORC1/PGC-1 axis promotes mitochondrial biogenesis and induces cellular senescence in the lung epithelium. Am. J. Physiol. Lung. Cell Mol. Physiol. 316, L1049-L1060.

Szabo, S. J., Sullivan, B. M., Stemmann, C., Satoskar, A. R., Sleckman, B. P., and Glimcher, L. H. (2002). Distinct effects of T-bet in TH1 lineage commitment and IFN-gamma production in CD4 and CD8 T cells. Science 295, 338-342. doi: 10.1126/science.1065543

Tassi, I., Cella, M., Gilfillan, S., Turnbull, I., Diacovo, T. G., Penninger, J. M., et al. (2007). p110gamma and p110delta phosphoinositide 3-kinase signaling pathways synergize to control development and functions of murine NK cells. Immunity 27, 214-227. doi: 10.1016/j.immuni.2007.07.014

Tee, A. R., Manning, B. D., Roux, P. P., Cantley, L. C., and Blenis, J. (2003). Tuberous sclerosis complex gene products, Tuberin and Hamartin, control mTOR signaling by acting as a GTPase-activating protein complex toward Rheb. Curr. Biol. 13, 1259-1268. doi: 10.1016/s0960-9822(03)00506-2

Thoreen, C. C., Chantranupong, L., Keys, H. R., Wang, T., Gray, N. S., and Sabatini, D. M. (2012). A unifying model for mTORC1-mediated regulation of mRNA translation. Nature 485, 109-113. doi: 10.1038/nature11083

Townsend, M. J., Weinmann, A. S., Matsuda, J. L., Salomon, R., Farnham, P. J., Biron, C. A., et al. (2004). T-bet regulates the terminal maturation and homeostasis of NK and Valpha14i NKT cells. Immunity 20, 477-494. doi: 10. 1016/s1074-7613(04)00076-7

Truitt, K. E., Mills, G. B., Turck, C. W., and Imboden, J. B. (1994). SH2-dependent association of phosphatidylinositol $3^{\prime}$-kinase $85-\mathrm{kDa}$ regulatory subunit with the interleukin-2 receptor beta chain. J. Biol. Chem. 269, 5937-5943.
Vezina, C., Kudelski, A., and Sehgal, S. N. (1975). Rapamycin (AY-22,989), a new antifungal antibiotic. I. Taxonomy of the producing streptomycete and isolation of the active principle. J. Antibiot. 28, 721-726. doi: 10.7164/antibiotics.28.721

Viel, S., Marcais, A., Guimaraes, F. S., Loftus, R., Rabilloud, J., and Grau, M. (2016). TGF-beta inhibits the activation and functions of NK cells by repressing the mTOR pathway. Sci. Sign. 9:ra19.

Vong, Q. P., Leung, W. H., Houston, J., Li, Y., Rooney, B., Holladay, M., et al. (2014). TOX2 regulates human natural killer cell development by controlling T-BET expression. Blood 124, 3905-3913. doi: 10.1182/blood-2014-06-58 2965

Vosshenrich, C. A., Ranson, T., Samson, S. I., Corcuff, E., Colucci, F., Rosmaraki, E. E., et al. (2005). Roles for common cytokine receptor gamma-chaindependent cytokines in the generation, differentiation, and maturation of NK cell precursors and peripheral NK cells in vivo. J. Immunol. 174, 1213-1221. doi: 10.4049/jimmunol.174.3.1213

Wang, F., Meng, M., Mo, B., Yang, Y., Ji, Y., Huang, P., et al. (2018). Crosstalks between mTORC1 and mTORC2 variagate cytokine signaling to control NK maturation and effector function. Nat. Commun. 9:4874.

Wang, S., Xia, P., Huang, G., Zhu, P., Liu, J., Ye, B., et al. (2016). FoxO1-mediated autophagy is required for NK cell development and innate immunity. Nat. Commun. 7:11023.

Yang, C., Siebert, J. R., Burns, R., Gerbec, Z. J., Bonacci, B., Rymaszewski, A., et al. (2019). Heterogeneity of human bone marrow and blood natural killer cells defined by single-cell transcriptome. Nat. Commun. 10:3931.

Yang, C., Siebert, J. R., Burns, R., Zheng, Y., Mei, A., Bonacci, B., et al. (2020). Single-cell transcriptome reveals the novel role of T-bet in suppressing the immature NK gene signature. Elife 9:e51339.

Yang, C., Tsaih, S. W., Lemke, A., Flister, M. J., Thakar, M. S., and Malarkannan, S. (2018). mTORC1 and mTORC2 differentially promote natural killer cell development. Elife 7:e35619.

Yang, G., Murashige, D. S., Humphrey, S. J., and James, D. E. (2015). A Positive Feedback Loop between Akt and mTORC2 via SIN1 Phosphorylation. Cell Rep. 12, 937-943. doi: 10.1016/j.celrep.2015.07.016

Yang, M., Chen, S., Du, J., He, J., Wang, Y., Li, Z., et al. (2016). NK cell development requires Tsc1-dependent negative regulation of IL-15-triggered mTORC1 activation. Nat. Commun. 7:12730.

Yang, M., Li, D., Chang, Z., Yang, Z., Tian, Z., and Dong, Z. (2015). PDK1 orchestrates early NK cell development through induction of E4BP4 expression and maintenance of IL-15 responsiveness. J. Exp. Med. 212, 253-265. doi: 10. 1084/jem.20141703

Yang, Q., and Guan, K. L. (2007). Expanding mTOR signaling. Cell Res. 17, 666-681.

Yang, Q., Inoki, K., Ikenoue, T., and Guan, K. L. (2006). Identification of Sin1 as an essential TORC2 component required for complex formation and kinase activity. Genes. Dev. 20, 2820-2832. doi: 10.1101/gad.1461206

Yang, Q., Li, F., Harly, C., Xing, S., Ye, L., Xia, X., et al. (2015). TCF-1 upregulation identifies early innate lymphoid progenitors in the bone marrow. Nat. Immunol. 16, 1044-1050. doi: 10.1038/ni.3248

Yip, C. K., Murata, K., Walz, T., Sabatini, D. M., and Kang, S. A. (2010). Structure of the human mTOR complex I and its implications for rapamycin inhibition. Mol. Cell 38, 768-774. doi: 10.1016/j.molcel.2010.05.017

Yokota, Y., Mansouri, A., Mori, S., Sugawara, S., Adachi, S., Nishikawa, S., et al. (1999). Development of peripheral lymphoid organs and natural killer cells depends on the helix-loop-helix inhibitor Id2. Nature 397, 702-706. doi: 10. $1038 / 17812$

Yu, Y., Yoon, S. O., Poulogiannis, G., Yang, Q., Ma, X. M., Villen, J., et al. (2011). Phosphoproteomic analysis identifies Grb10 as an mTORC1 substrate that negatively regulates insulin signaling. Science 332, 1322-1326. doi: 10.1126/ science.1199484

Zhang, J., Marotel, M., Fauteux-Daniel, S., Mathieu, A. L., Viel, S., Marcais, A., et al. (2018). T-bet and Eomes govern differentiation and function of mouse and human NK cells and ILC1. Eur. J. Immunol. 48, 738-750. doi: 10.1002/eji. 201747299

Zheng, X., Qian, Y., Fu, B., Jiao, D., Jiang, Y., Chen, P., et al. (2019). Mitochondrial fragmentation limits NK cell-based tumor immunosurveillance. Nat. Immunol. 20, 1656-1667.

Zhou, P., Zhang, N., Nussinov, R., and Ma, B. (2015). Defining the Domain Arrangement of the Mammalian Target of Rapamycin Complex Component Rictor Protein. J. Comput. Biol. 22, 876-886. 
Zhu, M. H., Berry, J. A., Russell, S. M., and Leonard, W. J. (1998). Delineation of the regions of interleukin-2 (IL-2) receptor beta chain important for association of Jak1 and Jak3. Jak1-independent functional recruitment of Jak3 to Il-2Rbeta. J. Biol. Chem. 273, 10719-10725.

Zinzalla, V., Stracka, D., Oppliger, W., and Hall, M. N. (2011). Activation of mTORC2 by association with the ribosome. Cell 144, 757-768.

Zwirner, N. W., and Ziblat, A. (2017). Regulation of NK Cell Activation and Effector Functions by the IL-12 Family of Cytokines: The Case of IL-27. Front. Immunol. 8:25. doi: 10.3389/fimmu.2017.00025
Conflict of Interest: The authors declare that the research was conducted in the absence of any commercial or financial relationships that could be construed as a potential conflict of interest.

Copyright (c) 2020 Yang and Malarkannan. This is an open-access article distributed under the terms of the Creative Commons Attribution License (CC BY). The use, distribution or reproduction in other forums is permitted, provided the original author(s) and the copyright owner(s) are credited and that the original publication in this journal is cited, in accordance with accepted academic practice. No use, distribution or reproduction is permitted which does not comply with these terms. 